\section{Mechanical Conditioning of Tomato Seedlings Improves Transplant Quality without Deleterious Effects on Field Performance}

\author{
Lauren C. Garner ${ }^{1}$ and Thomas Björkman ${ }^{2}$ \\ Department of Horticultural Sciences, New York State Agricultural Experiment \\ Station, Cornell University, Geneva, NY 14456-0462
}

Additional index words. Lycopersicon esculentum, mechanical conditioning, height control growth rate of the plant, and size differences at transplanting may not be overcome in the field. Furthermore, early flowers and fruit may be delayed or damaged because the last mechanical treatments are being applied during the development of the meristem that forms the first flower cluster. These problems could ultimately result in yield reduction. Mechanically conditioned tomato transplants show no adverse after-effects for greenhouse tomato production (Johijima and Latimer, 1992). The objective of our experiments was to determine if mechanical conditioning had an adverse effect on the field performance of processing and fresh market tomatoes.

\section{Materials and Methods}

Culture and treatment: processing tomatoes. 'Ohio 8245 ' processing tomatoes were seeded in 288-cell flats (Landmark Plastic Corp., Akron, Ohio) on 9 Apr. in 1992 through 1995. Each cell is $20 \mathrm{~mm}$ square, $44 \mathrm{~mm}$ deep, and has a volume of $9 \mathrm{~mL}$. The plants were grown in a greenhouse at $20{ }^{\circ} \mathrm{C}$ day $/ 15{ }^{\circ} \mathrm{C}$ night. They were fertilized twice weekly at watering with Peters Professional 20-20-20 fertilizer (Grace-Sierra Horticultural Products Co., Milpitas, Calif.; 20N-8.7P-16.6K) at an $\mathrm{N}$ concentration of $100 \mathrm{~g} \cdot \mathrm{m}^{-3}$. Mechanical conditioning treatments were begun when the leaf canopy closed, at which time the seedlings were $6 \mathrm{~cm}$ tall and $17 \mathrm{~d}$ old. The brushing treatment was applied with an unpainted, 25mm-diameter hardwood dowel pulled gently 20 times, back and forth, across the canopy at 8:30 AM each day for $\approx 15 \mathrm{~d}$ until the plants were moved outside. The impedance treatment was applied by suspending an acrylic sheet (4 mm thick) just below canopy height overnight (Samimy, 1993). The characteristics of the processing seedlings at transplanting were reported in Garner and Björkman (1997). Briefly, the treated plants were 3 to 4 $\mathrm{cm}$ shorter than the controls and the stems of impeded plants were $\approx 20 \%$ thicker.

After 4-5 d hardening in an outdoor cold frame, the seedlings were transplanted to the field at the Fruit and Vegetable Research Farm (Lima silt loam) in Geneva, N.Y., on 20 May in 1992 and 1993, and on 23 May in 1994 and 1995. A different field was used in each year. Plants were transplanted with a mechanical transplanter (Mechanical Transplanter Co., Holland, Mich.) in rows $1.25 \mathrm{~m}$ apart, with plants spaced $0.5 \mathrm{~m}$ apart in the row. Each plot was $12 \mathrm{~m}$ long. Treatments were laid out in a randomized complete block with three (199294) or five (1995) replications.

Culture and treatment: fresh-market tomatoes. 'Sunrise' fresh-market tomatoes were seeded on 5 Apr. 1994 and 1995, in 50-cell flats (Landmark) with cells $44 \mathrm{~mm}$ square and $55 \mathrm{~mm}$ deep, holding $66 \mathrm{~mL}$. The greenhouse conditions and fertilizer were the same as for processing transplants. Brushing treatments were begun when the leaf canopy closed, when seedlings were $28 \mathrm{~d}$ old. Twenty gentle strokes were applied daily for $20 \mathrm{~d}$ with an unpainted broomstick. At transplanting on 23 May, seedlings were $25 \mathrm{~cm}$ (control) and 20 
$\mathrm{cm}$ (brushed) tall in 1994, and $42 \mathrm{~cm}$ (control) and $31 \mathrm{~cm}$ (brushed) tall in 1995. The difference between treatments was significant at $P<$ 0.001 .

Plants were grown at the Fruit and Vegetable Research Farm in Geneva, N.Y. In 1994, plants were transplanted by hand onto bare ground in rows $1 \mathrm{~m}$ apart with $0.5 \mathrm{~m}$ between plants. In 1995, plants were transplanted with a water-wheel transplanter through black polyethylene mulch into raised beds $1.5 \mathrm{~m}$ apart with $0.3 \mathrm{~m}$ between plants; plots were $3 \mathrm{~m}$ long. The treatments were arranged as five paired plots. Suckers more than three nodes below the first flower cluster were removed before short-stake trellising (Peirce, 1987).

Data collection: processing tomatoes. For measuring recovery from transplant shock in processing transplants, the stem length of all plants from the soil level to the growing point was measured every 3 to $4 \mathrm{~d}$, until lateral growth became pronounced and stem length was no longer a valid estimate of the rate of plant growth. The stem diameter $2 \mathrm{~cm}$ above the cotyledons was measured $30 \mathrm{~d}$ after transplanting. The canopy area of young plants was estimated during the field season by measuring the diameter of the canopy of nine plants per plot. The time to flowering $(50 \%$ of the plants with open flowers) was determined from observations every 1 to $2 \mathrm{~d}$. The crop was harvested for yield when the fruit were full size and $\approx 50 \%$ were at the red ripe stage. The single hand harvest was on 17 Sept. 1992, 9 Sept. 1993, 1 Sept. 1994, and 25 Aug. 1995. Differences in yield and time to flowering were tested by one-way analysis of variance (Schaefer and Farber, 1992).

Data collection: fresh-market tomatoes. The time to flowering (50\% of the plants with open flowers) was determined from observations every 1 to $2 \mathrm{~d}$. Fruit were harvested weekly for 5 weeks beginning when $\approx 10 \%$ of the fruit were at the breaker stage (27 July 1994 and 12 July 1995). The early yield was the combined yield of the first 2 weeks. These harvests included all of the fruit produced at the first flower cluster of each plant. Harvest data were analyzed by paired $t$ test each year.

Wind tunnel. The effect of high wind on stem strain was studied in the Upson LowNoise Wind Tunnel (Mechanical and Aerospace Engineering Dept., Cornell Univ., Ithaca, N.Y.). Brushed and impeded plants of 'Ohio 8245 ' were compared to controls in separate tests of 72 plants each on the day that the plants would otherwise have been moved outside. Randomly selected plants were arranged in a 288-cell flat, taking care to minimize physical interaction among the plants. The flat was placed at the tunnel exit, in the region of uniform nonturbulent flow.

The susceptibility of plants to wind injury was measured as the amount of stem bending. The number of plants with the basal $1 \mathrm{~cm}$ of the stem bent $>45^{\circ}$ from vertical was recorded while the wind velocity was increased from 35 to $94 \mathrm{~km} \cdot \mathrm{h}^{-1}$. Wind velocity was increased once per minute in increments of $\approx 3 \mathrm{~km} \cdot \mathrm{h}^{-1}$. The wind-tunnel treatment did not break the stems. The data were analyzed as a logistic response to estimate the critical wind speed to bend half the untreated plants $\left(v_{c}\right)$, and the difference in critical wind speed due to conditioning $\left(v_{d}\right)$. The model

Wind speed $=v_{c}+v_{d}+\alpha \operatorname{logit}$ (proportion bent)

was fit to give estimates and standard deviations for each of the parameters $v_{c}, v_{d}$, and $\alpha$. Separate models were fit for each type of conditioning.

\section{Results and Discussion}

Growth of processing tomatoes. Tomato transplants that had been mechanically conditioned using brushing or impedance, while initially shorter, suffered no long-term growth effects after transplanting to the field. Neither treatment delayed recovery from transplant shock: stem elongation resumed on the same day in all treatments (Fig. 1). Rapid elongation began after $15 \mathrm{~d}$ in 1994 and $17 \mathrm{~d}$ in 1995 . In 1995 , a few cold days 15 to $17 \mathrm{~d}$ after transplanting slowed growth. There is some con- solidation of the soil immediately after transplanting that results in an artifactually negative apparent growth rate. The close correspondence in elongation rate among the treatments, even as the rate fluctuated, emphasizes that there is no lingering growth inhibition.

The three treatments began to flower within a day of each other (Table 1). Four weeks after transplanting, there were no significant differences between treatments in stem diameter or canopy area (Table 2).

Thus, the amount of mechanical stimulus that was sufficient for effective height control of tomato transplants did not have significant long-term effects on the growth rate of the plants after transplanting. This result is consistent with the finding that many plant species quickly resume growth after mechanical stimulation. The rate of stem elongation is the same as, or higher than, controls within 3 to $4 \mathrm{~d}$ after the discontinuation of mechanical stimulation (Jaffe, 1973).

Reproductive development offresh-market tomatoes. There are additional concerns about the effects of conditioning on subsequent de-

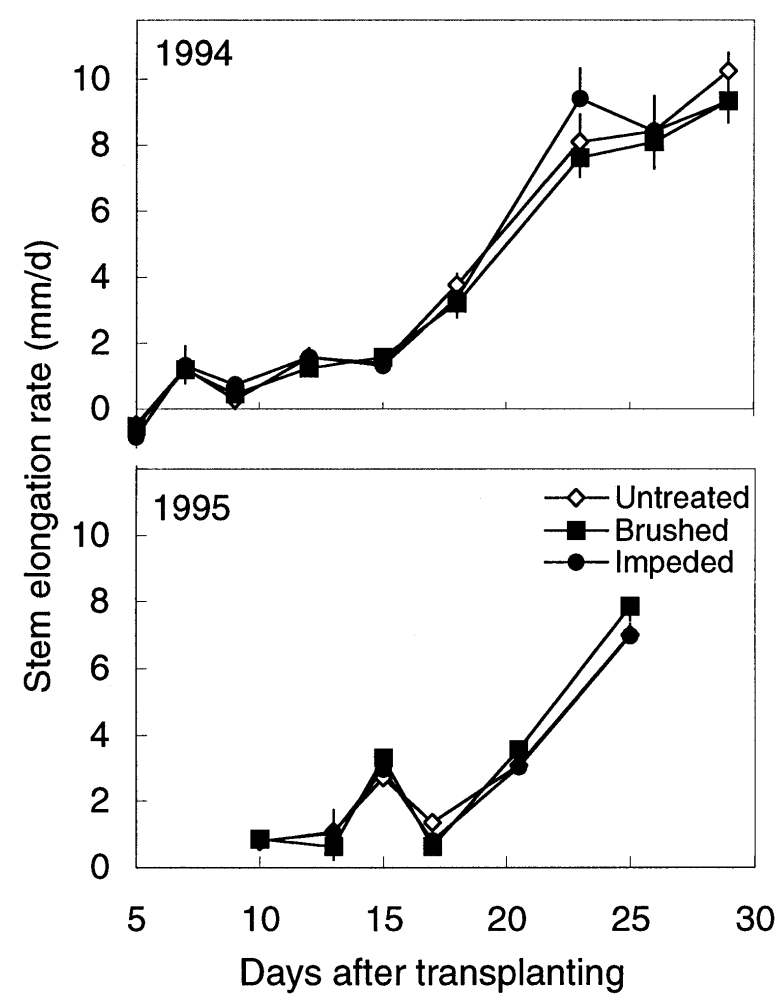

Fig 1. Effect of mechanical conditioning on stem elongation following transplant shock in 'Ohio 8245 ' processing tomato transplants. The stem elongation rate is the mean for the period since the previous measurement. The vertical bars are the standard error, when it exceeds the size of the symbol.

Table 1. Effect of mechanical conditioning on time to flowering in processing and fresh-market tomatoes. No variations among treatments were statistically significant at $P<0.05$.

\begin{tabular}{lcccc}
\hline \multirow{2}{*}{$\begin{array}{l}\text { Conditioning } \\
\text { treatment }\end{array}$} & \multicolumn{2}{c}{ Time to 50\% anthesis (days after transplanting) } \\
\cline { 2 - 4 } \cline { 2 - 5 } & 1994 & 37.8 & & \multicolumn{2}{c}{ Fresh market } \\
\hline None & 36.0 & 37.4 & 23.2 & 1995 \\
Brushed & 36.0 & 38.2 & 21.6 & 24.6 \\
Impeded & 35.7 & 0.46 & --- & --- \\
$F$ & 0.09 & & 1.60 & 0.66 \\
\hline
\end{tabular}


Table 2. The effect of brushing and impedance on field growth of processing tomato transplants. Stem diameter and canopy area 4 weeks after transplanting. No variations among treatments were statistically significant at $P<0.05$

\begin{tabular}{lcc}
\hline $\begin{array}{l}\text { Conditioning } \\
\text { treatment }\end{array}$ & $\begin{array}{c}\text { Stem diameter } \\
(\mathrm{mm})\end{array}$ & $\begin{array}{c}\text { Canopy } \\
(\% \text { of ground area })\end{array}$ \\
\hline None & $\begin{array}{c}1993 \\
\text { Brushed }\end{array}$ & $9.0 \pm 1.0$ \\
Impeded & $6.9 \pm 0.6$ & $8.8 \pm 0.5$ \\
$F$ & $6.8 \pm 0.5$ & $8.8 \pm 0.5$ \\
& 0.33 & 0.04 \\
None & 1994 & \\
Brushed & $6.4 \pm 0.5$ & $2.2 \pm 0.4$ \\
Impeded & $6.5 \pm 0.5$ & $1.8 \pm 0.4$ \\
$F$ & $7.3 \pm 0.7$ & $2.0 \pm 0.4$ \\
& 0.70 & 0.23 \\
None & 1995 & $2.2 \pm 0.4$ \\
Brushed & $5.4 \pm 0.3$ & $2.2 \pm 0.2$ \\
Impeded & $6.0 \pm 0.2$ & $2.2 \pm 0.2$ \\
$F$ & $6.2 \pm 0.5$ & 0.16 \\
\hline
\end{tabular}

${ }^{2}$ Standard error of the mean; $\mathrm{n}=3$ in 1993 and 1994, $\mathrm{n}=5$ in 1995.

Table 3. The effect of mechanical conditioning on yield of processing tomato cv. Ohio 8245 . No variations among treatments were statistically significant at $P<0.05$

\begin{tabular}{lllll}
\hline \hline Conditioning & \multicolumn{4}{l}{ Fruit yield $\left(\mathrm{kg} \cdot \mathrm{m}^{-2}\right)$} \\
\cline { 2 - 5 } treatment & 1992 & 1993 & 1994 & 1995 \\
\hline None & 5.1 & 8.3 & 6.7 & 7.3 \\
Brushed & 4.9 & 7.7 & 6.1 & 7.2 \\
Impeded & $-^{\mathrm{z}}$ & 8.1 & 7.7 & 7.3 \\
$F$ & 0.70 & 0.35 & 0.57 & 0.01 \\
\hline
\end{tabular}

${ }^{2}$ Treatment not applied.

Table 4 . The effect of brushing on the early and total yield of fresh market tomatoes cv. Sunrise. Early yield was the first 2 weeks' harvest. No differences were significant at $P<0.05$.

\begin{tabular}{|c|c|c|c|c|}
\hline \multirow{3}{*}{$\begin{array}{l}\text { Conditioning } \\
\text { treatment }\end{array}$} & \multicolumn{4}{|c|}{ Fruit yield $\left(\mathrm{kg} \cdot \mathrm{m}^{-2}\right)$} \\
\hline & \multicolumn{2}{|c|}{1994} & \multicolumn{2}{|c|}{1995} \\
\hline & Early & Total & Early & Total \\
\hline None & $1.4 \pm 0.2^{z}$ & $7.3 \pm 0.7$ & $1.1 \pm 0.1$ & $9.3 \pm 0.4$ \\
\hline Brushed & $1.5 \pm 0.2$ & $7.3 \pm 0.5$ & $1.2 \pm 0.1$ & $9.6 \pm 0.6$ \\
\hline$t$ & 0.19 & 0.02 & 0.96 & 0.42 \\
\hline
\end{tabular}

${ }^{\mathrm{z}}$ Standard error of the mean.

velopment of transplants for fresh market because they are older than transplants used for processing. Floral evocation occurs while the brushing treatments are being applied; therefore, flowering could be delayed, or flowers and fruits could have structural abnormalities. Such changes have resulted from other methods of height control. Shaking delayed flowering (Akers and Mitchell, 1985) and daminozide delayed first fruit set (Jaworski et al., 1970). Late or distorted fruits are not tolerated by growers because earliness and cosmetic perfection are essential for the fresh market.

In our experiments, mechanical conditioning did not affect the number of days to first flower or early yield of fresh-market tomatoes. Brushed tomato plants reached $50 \%$ flowering at the same time as untreated plants (Table 1). Early fruit production was not reduced by brushing (Table 4), so early flowers must have been functionally normal. The only defect found was blossom-end rot, and it was unaffected by brushing (data not shown). Therefore, neither earliness nor fruit and flower structure were affected by brushing.
These results are consistent with those of other researchers (Johijima and Latimer, 1992) and with results obtained using processing tomatoes: brushing, unlike shaking and daminozide, can be used to reduce stem elongation of transplants without harming flower or fruit development.

Yield. The yield of processing (Table 3) and fresh-market tomatoes (Table 4) was equal among the treatments in all years. This result reinforces earlier observations that, while mechanical conditioning during crop production often reduces tomato yield (Akers and Mitchell, 1985; Johijima and Latimer, 1992), pretransplant conditioning typically does not (Johijima and Latimer, 1992).

Effects on wind tolerance-wind tunnel. Mechanical conditioning before transplanting may increase transplant survival during certain adverse field conditions. Wind is an important cause of transplant mortality. To investigate the effects of mechanical conditioning treatments on wind resistance, processing tomato transplants were tested in a wind tunnel. Mechanically conditioned plants toler- ated higher wind speeds before bending more than $45^{\circ}$ than did untreated plants. The wind speed tolerated by the seedlings was $4.4 \pm 1.0$ $\mathrm{km} \cdot \mathrm{h}^{-1}$ higher(Fig. 2A) if they had been brushed on 10 consecutive mornings, and $12.5 \pm 2.0$ $\mathrm{km} \cdot \mathrm{h}^{-1}$ higher (Fig. 2B) if they had been impeded for 10 consecutive nights.

Effects on wind tolerance-field. In all plantings but one, mortality was too low to analyze. The exception was the 1995 freshmarket trial. The number of plants that had died was recorded for the first 2 weeks after transplanting. Three days after transplanting in 1995, a storm resulted in a maximum quarter-hour wind speed of $71 \mathrm{~km} \cdot \mathrm{h}^{-1}$ at the Research Farm weather station. The calculated wind speed at plant height was $53 \mathrm{~km} \cdot \mathrm{h}^{-1}(\mathrm{Rae}$ and Pope, 1984). Plants were broken off at the base, or were cracked near the base soon after the storm. Untreated plants had a higher mortality rate than brushed plants (12\% of controls, $2 \%$ of brushed, $P<0.1$ ). In the single event of injurious wind experienced in our field trials, brushed plants had significantly lower mortality than control plants. 
Conclusions. Mechanical conditioning had no negative consequences on field performance of tomato transplants, and improved their resistance to wind injury. We used two kinds of mechanical conditioning, brushing and impedance, to reduce excess elongation and thereby make plants easier to transplant. After transplanting, mechanically conditioned plants resumed growing at precisely the same time as the controls, flowered at the same time, and yielded the same. In fresh-market plants, there was no delay in early fruit production, nor was mechanical conditioning associated with any developmental defects in the first fruits. In a wind tunnel, conditioned plants withstood somewhat higher wind speed, indicating a benefit in addition to improved transplant handling.

\section{Literature Cited}

Adler, P.R. and G.E. Wilcox. 1987. Influence of thigmic stress or chlormequat chloride on tomato morphology and elemental uptake. J. Plant Nutr. 10:831-840.

Akers, S.W. and C.A. Mitchell. 1985. Seismic stress effects on reproductive structures of tomato, potato, and marigold. HortScience 20:684 686.
Biddington, N.L. 1986. The effects of mechanically-induced stress in plants-A review. Plant Growth Regulat. 4:103-123.

Garner, L.C. and T. Björkman. 1996. Mechanical conditioning for controlling excessive elongation in tomato transplants: Sensitivity to dose, frequency and timing of brushing. J. Amer. Soc. Hort. Sci. 121:894-900.

Garner, L.C. and T. Björkman. 1997. Using impedance for mechanical conditioning of tomato transplants to control excessive stem elongation. HortScience 32:227-229.

Heuchert, J.C., J.S. Marks, and C.A. Mitchell. 1983. Strengthening of tomato shoots by gyratory shaking. J. Amer. Soc. Hort. Sci. 108:801-805.

Jaffe, M.J. 1973. Thigmomorphogenesis: The response of plant growth and development to mechanical stimulation, with special reference to Bryonia dioica. Planta 114:143-157.

Jaffe, M.J. and R. Biro. 1979. Thigmomorphogenesis: The effect of mechanical perturbation on the growth of plants with special reference to anatomical changes, the role of ethylene, and interaction with other environmental stresses, $\mathrm{p}$. 25-59. In: H. Mussell and R.C. Staples (eds.) Stress physiology of crop plants. Wiley, New York

Jaworski, C.A., R.E. Webb, S.A. Garrison, E.L. Bergman, and S. Shannon. 1970. Growth-retardant-treated tomato transplants. HortScience 5:255-256.
Johijima, T. and J.G. Latimer. 1992. Brushing influences transplant growth and subsequent yield of four cultivars of tomato and their hybrid lines. J. Amer. Soc. Hort. Sci. 117:384-388.

Latimer, J.G. 1994. Pepper transplants are excessively damaged by brushing. HortScience 29:1002-1003

Latimer, J.G., T. Johijima, and K. Harada. 1991. The effect of mechanical stress on transplant growth and subsequent yield of four cultivars of cucumber. Scientia Hort. 47:221-230.

Latimer, J.G. and C.A. Mitchell. 1988. Effects of mechanical stress or abscisic acid on growth, water status, and leaf abscisic acid content in eggplant seedlings. Scientia Hort. 36:37-46.

Latimer, J.G. and P.A. Thomas. 1991. Application of brushing for growth control of tomato transplants in a commercial setting. HortTechnology 1:109-110.

Peirce, L.C. 1987. Vegetables: Characteristics, production and marketing. Wiley, New York.

Rae, W.H. and A. Pope. 1984. Low-speed wind tunnel testing. Wiley, New York.

Samimy, C. 1993. Physical impedance retards top growth of tomato transplants. HortScience 28:883-885.

Schaefer, R.L. and E. Farber. 1992. The student edition of MINITAB, Release 8. AddisonWesley, New York.

Shaw, L.N. 1993. Changes needed to facilitate automatic transplanting. HortTechnology 3:418-420. 